\title{
A Message of Gratitude and the State of JAMS in 2021
}

\section{Billy Tringali}

It is no small feat to launch an academic journal, and no smaller feat to ensure its continuation past the initial excitement for a new project. Luckily, though my name is the one most prominent on this project, JAMS is not the product of this author alone and that is how we have this second issue.

For this journal to exist, hundreds of hours of labor were required from scholars all around the world. From authors in Japan and the United Arab Emirates, to peer reviewers in Canada and Scotland, so many have dedicated their time and expertise to breathing life into JAMS' mission of exploring anime as an art form and bringing visibility to the deeper meanings, understandings, and cultural significance of anime, manga, cosplay, and their fandoms. For this outpouring of support for not only JAMS as a journal, but anime studies as a field, I have so much gratitude to give.

The Journal of Anime and Manga Studies is run entirely by volunteers. I give my enormous thanks to JAMS Editorial Board members, Maria Bonn, Kay K. Clopton, Mark Gellis, Andrea Horbinski, Frenchy Lunning, and Elizabeth Wickes, whose advice on and support of this publication is a mainstay in its success. My deepest gratitude must also go out to JAMS' many peer reviewers whose comments and suggestions strengthened the pieces present in our second volume, and those that may be resubmitted for future volumes. Thank you as well to the authors published in this issue, as well as all those who submitted their pieces and those who are considering publishing with JAMS in the future. JAMS would not be the project it is without all of you. 
In my last 'Letter from the Editor,' I noted that I hoped JAMS “can exist as a space that publishes high-quality scholarship about anime, manga, cosplay, and their fandoms." I am thrilled to see that this dream has come to pass in our second volume. At close to 300 pages, JAMS' second volume is more than 100 pages longer than our first issue, and received double the number of submissions. I'm also over the moon to report that our first volume, one year from its initial publication, has received over 8,00o abstract and file views. For a small journal in a still-niche area of study, I consider this number to be staggering.

Such a strong response to - and such a powerful engagement with - JAMS seems to be a testament to not only the ever-expanding interest in anime and manga all around the world, but to the increasing enthusiasm for anime and manga studies as a discipline. This response has meant so much to me, especially during the nightmarish year that has been 2021. Being able to speak to so many people in so many different nations during the course of managing this volume, being able to read such fascinating work, and being able to see the Journal of Anime and Manga Studies referenced, spoken about, and shared on social media has filled me with so much excitement. I hope the papers you read in this volume will imbue you with the same feeling.

Thank you for reading the second volume of the Journal of Anime and Manga Studies.

With warmth, Billy Tringali Editor-In-Chief 


\section{Dedication}

\section{Billy Tringali}

I would like to dedicate the second volume of the Journal of Anime and Manga Studies to two individuals who have supported JAMS' since its inception.

\section{Jessica Parent and Maria Alberto}

Beyond serving as JAMS' copy editors, your advice, support, collegiality, and most importantly, friendship, has been of unfathomable assistance throughout the building of JAMS' second volume. I hope that this dedication can express just how grateful I am for you, and not embarrass you too much. 